\title{
Consideraciones en la Atención Odontológica de Urgencia en Contexto de Coronavirus COVID-19 (SARS-CoV-2)
}

\author{
Urgency Dental Care Considerations in the Context \\ of Coronavirus COVID-19 (SARS-CoV-2)
}

\author{
Cristóbal Sepúlveda Verdugo'; Alfio Secchi Álvarez² \& Francisca Donoso-Hofer ${ }^{3}$
}

SEPÚLVEDA, V. C.; SECCHI, A. A. \& DONOSO-HOFER, F. Consideraciones en la atención odontológica de urgencia en contexto de coronavirus COVID-19 (SARS-CoV-2). Int. J. Odontostomat., 14(3):279-284, 2020.

RESUMEN: Los Coronavirus son una familia de virus de amplia distribución en la naturaleza presentes principalmente en los animales. El Covid-19 es la enfermedad causada por el coronavirus (SARS-CoV-2), que fue identificado y caracterizado en enero de 2020 en China. Los profesionales del área odontológica deben tomar todas las medidas de protección al tener que realizar una atención de urgencia, lavado de manos y utilización de equipos de protección personal. Para cada una de las urgencias odontológicas consideradas en la guía del Ministerio de Salud de Chile se dan recomendaciones para el actuar y posterior desechos e higienización de materiales. El objetivo de este artículo de revisión es entregar recomendaciones actualizadas y atingentes a nuestra realidad nacional a fin de disminuir las posibilidades de contagio ante la exposición inminente de pacientes sospechosos o que pudiesen presentar Covid-19

PALABRAS CLAVE: Urgencia dental, SARS-Cov2, Covid-19.

\section{INTRODUCCIÓN}

La situación mundial producida por la pandemia del COVID-19 nos ha llevado a replantearnos todas las formas de relación humana pre existentes. Su alta tasa de contagiabilidad así como también las vías de transmisión conocidas a la fecha: Tos, estornudos, pequeñas gotas de saliva y contacto de las mucosas nasal, oral y ocular convierten a los odontólogos y al personal de apoyo odontológico a los profesionales más expuestos y vulnerables al momento de ejercer su trabajo.

Los Coronavirus son una familia de virus de amplia distribución en la naturaleza presentes principalmente en los animales. Se conocían cuatro coronavirus que afectan frecuentemente al ser humano produciendo principalmente el resfrío común. El año 2002 emergió un nuevo Coronavirus, denominado SARS (síndrome respiratorio aguda severo) en China que tuvo un total de ocho mil casos con un $10 \%$ de mortalidad y que fue contenido sin reportarse nuevos casos desde 2003. El 2012 emerge MERS (síndrome respiratorios del medio oriente) en la península arábica con alrededor de tres mil casos a la fecha y con una mortalidad de cercana al $40 \%$ (Colegio Médico de Chile \& Sociedad Chilena de Infectología, 2020).

El Covid-19 es la enfermedad causada por un nuevo coronavirus (SARS-CoV-2), que fue identificado y caracterizado en enero de 2020 en China. La epidemia se originó a partir de animales salvajes, donde Covid-19 se ha relacionado con serpientes, murciélagos y pangolines (Ji et al., 2020). Aún no se tiene certeza de cómo surgió el traspaso del virus interespecie.

De acuerdo con el último reporte de la Organización Mundial de la Salud, hasta el 30 de marzo de 2020, los países han notificado un total de 693.224

\footnotetext{
${ }^{1}$ Cirujano Dentista, Pasante Servicio Cirugía Maxilofacial, Hospital San Juan de Dios, Santiago de Chile, Chile.

${ }^{2}$ Cirujano Dentista, Pasante Servicio Cirugía Maxilofacial, Complejo Asistencial Barros Luco Trudeau, Santiago de Chile, Chile.

${ }^{3}$ Profesor asistente, Departamento de Cirugía Máxilofacial - Facultad de odontología, Universidad de Chile, Chile.
} 
casos confirmados con 33.106 personas fallecidas por COVID-19 (World Health Organization, 2020).

El tiempo de duplicación de los casos es actualmente de 11 días y el tiempo de duplicación de las muertes es de 8 días, con tiempos más extendidos en países que han realizado medidas de mitigación efectivas como China o Corea del Sur (Roser et al., 2020). Por lo anteriormente mencionado, al momento que usted lea esta publicación, la notificación de casos confirmados, el número de fallecidos y los países afectados sean exponencialmente mayor que los descrito.

Los pacientes y profesionales dentales pueden estar expuestos a agentes patógenos microorganismos, incluidos virus y bacterias que infectan la boca cavidad y tracto respiratorio. Los entornos de cuidado dental invariablemente llevan al riesgo de infección de coronavirus COVID-19 debido a la especificidad de su procedimientos, que implica la comunicación cara a cara con pacientes y exposición frecuente a saliva, sangre y a otros fluidos.

Según la información disponible en el Departamento de Estadísticas e Información en Salud de Chile (DEIS), del total de consultas de urgencia nacionales, un 20,4\% correspondió a urgencias odontológicas ambulatorias (Ministerio de Salud, 2011). Por lo que no es descabellado pensar que la urgencia dental es un importante lugar de pacientes que podrían ser fuentes de contagio.

El objetivo de este artículo de revisión es entregar recomendaciones actualizadas y atingentes a nuestra realidad nacional a fin de disminuir las posibilidades de contagio ante la exposición inminente de pacientes sospechosos o que pudiesen presentar COVID-19

\section{Barreras de protección y consideraciones previas}

El lavado de manos es considerado uno de los puntos más críticos para reducir la contaminación por partículas virales. Este lavado de manos debe ser realizado por el profesional antes y después de cada atención, así como también por los pacientes, quienes al menos deben higienizar sus manos con alcohol gel o similar, previo y posterior a la atención (Araya, 2020). Los dentistas también deben tomar medidas estrictas de bioseguridad para la protección de piel y mucosas, para ello se recomienda la utilización de mascarillas con filtro de partículas FFP2 o tipo N95, guantes de examen, lentes de protección o mascarillas con vise- ras faciales junto con delantal de aislamiento desechable (Peng et al., 2020), además del retiro de todo accesorio o joya que se encuentre en área de riesgo a contacto con fluidos (Consejo General de Colegios de Odontólogos y Estomatólogos de España, 2020).

El lugar de atención debe ser desinfectado previa e inmediatamente posterior a la atención de pacientes confirmados o con sospecha de Covid-19, esto incluye área administrativa con computadores o televisor (Consejo General de Colegios de Odontólogos y Estomatólogos de España). Se le debe dar máxima importancia a estas acciones para evitar una mayor propagación del virus. Se ha comprobado la permanencia de COVID-19 en superficies inanimadas durante tiempos que pueden variar entre dos horas hasta nueve días (Geller et al., 2012). Diversos tipos de agentes biocídas, como peróxido de hidrógeno fue efectivo con una concentración de $0,5 \%$ y un tiempo de incubación de un minuto. Hipoclorito de sodio requirió una concentración mínima de al menos 0,21\% para ser efectivo y aprobado para la desinfección, principalmente en entornos sanitarios La utilización de colutorio de clorhexidina no se recomienda, por su baja efectividad para la eliminación del virus (Kampf, 2018). Con respecto al paciente, para la higiene de la zona peri oral se recomienda utilizar povidona yodada 10 $\%$, así como también extremar medidas con campos estériles. En la cavidad oral la elección debe ser un antiséptico que permita una adecuada disminución de la carga salival del virus sin generar daño en la mucosa oral.

El peróxido de hidrógeno (agua oxigenada), se recomienda en una dilución al $1 \%$. Para obtener 15 $\mathrm{mL}$ de enjuague, se puede utilizar $5 \mathrm{~mL}$ de peróxido de hidrógeno adicionando $10 \mathrm{~mL}$ de agua destilada (Araya; Peng et al.).

\section{Patologías odontológicas de urgencia}

La Guía de Urgencia Odontológica propuesta por el Ministerio de Salud de Chile (GES) clasifica como urgencias a pericoronaritis, patología pulpar inflamatoria, infecciones odontogénicas, gingivitis y periodontitis ulcero necrotizante, trauma dento alveolar y complicaciones post exodoncia. Todas ellas presentan como síntoma principal el dolor las cuales deben ser a lo menos evaluadas a través de un examen intra oral para un adecuado tratamiento.

Por su parte la American Dental Association (ADA) plantea dentro del manejo de urgencia dental 
las patologías ya mencionadas agregando biopsia de tejidos anormales, cementaciones de prótesis fijas unitarias o plurales cuyos provisionales se hayan extraviado y exista daño en mucosa y/o encía. Así como tambien menciona dentro del manejo de emergencia a sangrados profusos, procesos infecciosos difusos que puedan comprometer vía aérea y trauma de huesos faciales con potencial compromiso de vía aérea (American Dental Association, 2020).

Muchas veces, para la resolución de alguna de estas patologías como la patología pulpar inflamatoria conocida comúnmente como pulpitis, es necesario el uso de instrumental rotatorio de alta velocidad para acceder a la pulpa dental, extraerla y aplicar una medicación intraconducto que elimine el dolor y detenga su progresión a un proceso infeccioso más complicado. El uso de este tipo de instrumental posee un riesgo adicional considerando que el spray o aerosol que se forma al funcionar mezclado con saliva del paciente dispersa las partículas virales que pueden tener contacto directo hacia el profesional y con superficies de contacto (Peng et al.) (sillón dental, lámpara y anexos) que son importantes a considerar.

Si el cuadro inflamatorio pulpar, ya sea reversible como irreversible no cede frente a analgésicos anti inflamatorios , la indicación terapéutica es realizar una trepanación de urgencia en primera instancia con elementos no rotatorios como cucharetas de caries y si esto no es posible, con instrumental rotatorio de baja velocidad. En ambos casos, bajo aislación con goma dique e irrigación localizada con uso de aspiración constante (Meng et al., 2020).

El uso de agentes quimio-mecánicos (Carisolv) compuestos por aminoácidos e hipoclorito de sodio para la remoción de caries cavitadas y profundas está avalado por la evidencia y no utiliza instrumental rotatorio, además existe una menor percepción de dolor por parte del paciente; en su desventaja se encuentra el aumento de tiempo operatorio de hasta 2,5 veces mas (en comparación con el uso de instrumental rotatorio) y el alto costo por dosificación (Maru et al., 2015).

La prescripción de antibiótico en conjunto con AINES versus solo AINES para el manejo de dolor posterior al procedimiento no posee evidencia significativamente relevante según la guía Cochrane actualizada (Agnihotry et al., 2019).

En el caso de las urgencias de patologías periodontales como una gingivitis periodontitis ulcero necrotizante cuya sintomatología no cede frente al uso de AINE y tratamiento antibiótico que por lo general corresponde a Amoxicilina y metronidazol. La clindamicina continúa siendo el tratamiento de elección en pacientes alérgicos a betalactámicos (Liñares \& Martín-Herrero, 2003). Se recomienda la no utilización de ultrasonido, más bien, solo debridación con instrumental manual como curetas o jackets junto con la irrigación de suero fisiológico, clorhexidina o peróxido de hidrógeno localizado con aspiración constante.

Otros procedimientos terapéuticos que involucren invasión en tejidos blandos y espacios faciales como por ejemplo el tratamiento de pericoronaritis, alveolitis, drenaje de abscesos y exodoncias, es necesario evaluar si efectivamente es necesario realizar la intervención o puede manejarse con analgésicos y antibióticos. Si producto de estas patologías hay compromiso del estado general o el proceso infeccioso por las condiciones sistémicas del paciente o por su localización anatómica pudiese progresar comprometiendo la vía aérea es necesario realizar la intervención.

Con este objetivo, idealmente se deben seguir protocolos de bioseguridad similares a pabellón quirúrgico, uso de bata y campos estériles, mascarilla, lentes y/o pantalla facial como las especificadas anteriormente. Posterior a un tratamiento en el que exista la necesidad de sutura, se recomienda el uso de materiales reabsorbibles, a fin de no tener que realizar procedimientos posteriores para su retiro, evitando exponer al paciente y personal a escenarios de contagio (Meng et al.).

Frente a los distintos tipos de trauma dentoalveolar, el material utilizado como jeringas de ácido orto fosfórico, adhesivo y resina para efectuar las ferulizaciones al no ser desechable, debe ser desinfectado inmediatamente posterior al uso con alcohol al $70 \%$ (Watanabe et al., 2018). Además se debe utilizar resina fluida para con esto disminuir las necesidades de pulido con instrumental rotatorio y utilización de jeringa triple.

A la fecha de este artículo, no existe evidencia sólida de la conducta a seguir en relación con el uso de materiales de osteosíntesis ya que se desconoce cómo el virus se comporta frente a su contacto. Con respecto al trauma maxilofacial, la Asociación para Estudio de Osteosíntesis en su grupo de especialistas maxilofaciales (AO CMF) recomiendan intervenir en fracturas que comprometan funcionalidad, sean un potencial riesgo vital o no exista estabilidad; en el caso 
de fracturas mandibulares, utilizar bloqueo intermaxilar si la estabilidad y desplazamiento son favorables (considerar elásticos de ortodoncia que puedan ser cortados con tijeras frente a episodios de tos o disnea). En caso de necesitar reducción abierta y fijación interna rígida, realizar procedimiento con el mínimo personal necesario, preferir uso bisturí frío, tornillos autoperforantes y osteotomos evitando el aerosol producido por el motor quirúrgico con irrigación, sierra neumática o el piezoeléctrico. De ser necesario el uso de motor quirúrgico disminuir velocidad de rotación (Grant et al., 2020).

Actualmente diversas asociaciones y autores han compartido evidencia consistente en lo que respecta los cuidados en la atención dental. Las recomendaciones se basan en los aportes periódicos de publicaciones científicas relacionadas con el comportamiento del COVID-19. En caso de la atención de tratamientos electivos la recomendación es en contra a la realización, a diferencia de la atención categorizada como emergencia-urgencia, en donde es a favor.

Como autores no podemos clasificar aún estas recomendaciones como Fuertes o Débiles (según criterio GRADE) debido a la rápida y variada divulgación de publicaciones que traen consigo estudios observacionales de bajo nivel de evidencia.
La ADA clasifica como Emergencia dental todo cuadro que sea una potencial amenaza a la vida y necesite un tratamiento inmediato. En contraste, define a Urgencia como todo cuadro que debe ser manejado de inmediato para aliviar dolor severo, riesgo de infección o aumento de severidad de ella y/o aumento de carga en la atención hospitalaria; estos procedimientos deben ser manejados de manera mínimamente invasiva (Tabla I, American Dental Association).

\section{Exámenes complementarios}

Para la solicitud de exámenes imagenológicos considerar utilización de técnicas extraorales con el objetivo de disminuir la posibilidad de contagio en el personal técnico.

Es necesario individualizar cada caso clínico, debido a la pérdida de rendimiento que las técnicas extraorales presentan en el diagnóstico de patologías pulpares o apicales.

El uso de tomografía computada conebeam en el área maxilofacial presenta beneficios en rendimiento volumétrico y no involucra un contacto directo con saliva del paciente; aunque aspectos económicos lo sitúan en desventaja (Araya).

Tabla I. Esquema de clasificación de atenciones. V.A: Vía Aérea. Aportes de Guía Minsal (GES) y American Dental Association (ADA) . Sugerimos al tratante individualizar cada caso clínico.

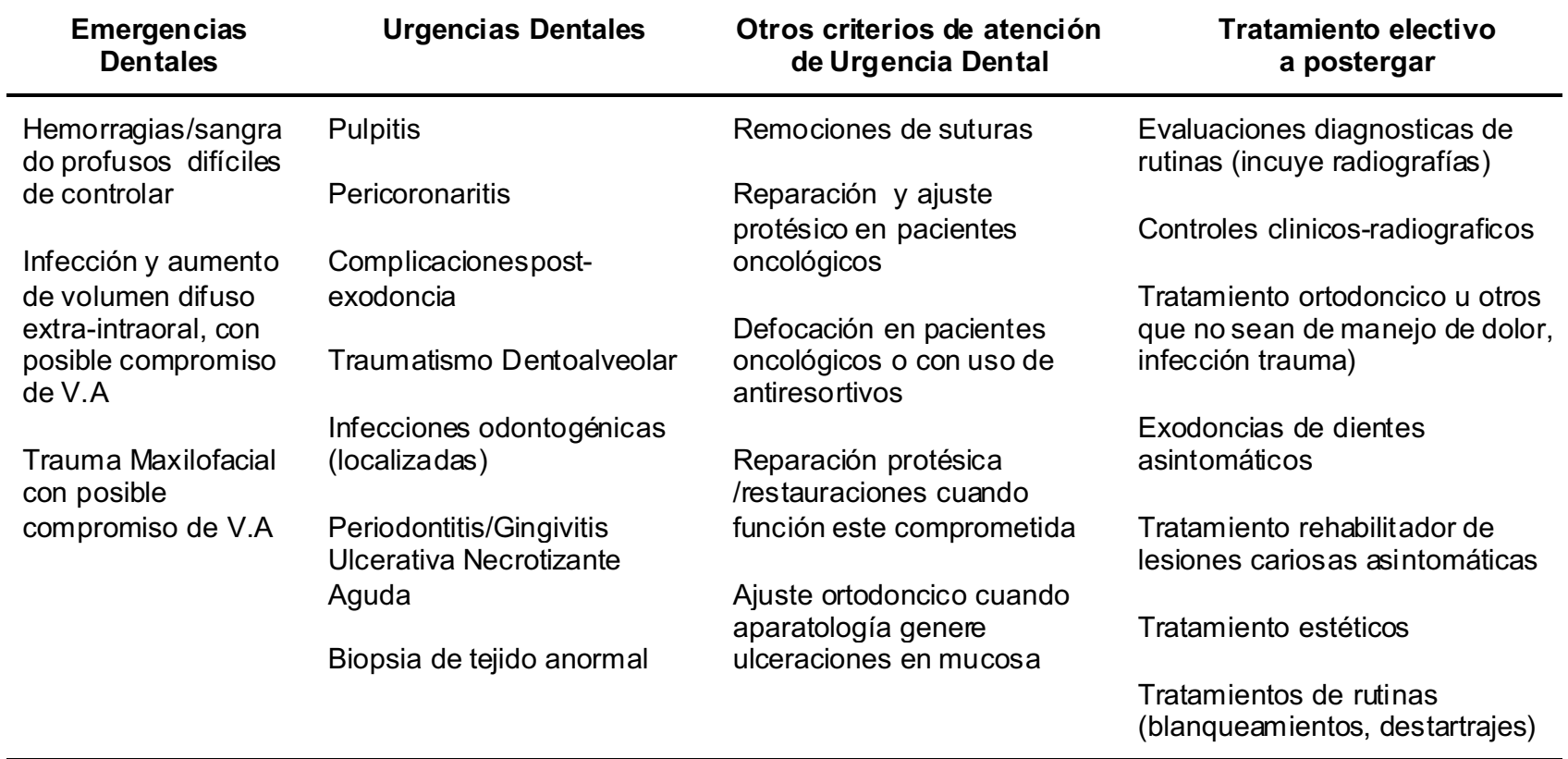


Considere la utilización de protectores plásticos y aseo en el caso de requerir el uso de técnicas intraorales, de igual manera dar aviso al personal acerca de la condición del paciente.

\section{Higiene y desechos posterior a la atención}

Las recomendaciones frente al desecho de batas, campos y guantes se basan en la exposición de estos frente a fluidos contaminados, específicamente su parte anterior, es por eso que su retiro debe ser con precaución comenzando por sujetar el delantal (con los guantes) desde su parte anterior alejándolo del cuerpo hasta que se rompan los lazos, mientras se quita la bata se debe enrollar desde adentro hacia afuera en un paquete hasta retirar los guantes tocándolos desde su parte interna y posteriormente tocando la bata enrollada con las manos desnudas, depositando todo en un contenedor de desechos indicado. Lavar las manos con agua y jabón en caso de exponerlas al contacto con material contaminado o por sospecha (Kampf; Peng et al.).

\section{Otras consultas odontológicas}

Cabe destacar que frente a la consulta de pacientes positivos para COVID-19 por tratamientos no clasificados dentro de la categoría urgencia, es decir, atención electiva, por el alto riesgo a contagio, la recomendación es postergar (Araya).

La atención odontológica no urgente en el contexto de una pandemia puede resultar bastante intrascendente, sin embargo, hay tratamientos odontológicos que no son una urgencia en si, pero de su realización depende que otros procedimientos se lleven a cabo en los pacientes. Tal es el caso de las defocaciones dentales previo a inicio de Quimio y radioterapia, inicio terapia con bifosfonatos y preparación odontológica previo a transplante de médula u órgano sólido por mencionar algunas situaciones.

Si bien estos pacientes no necesariamente tienen COVID-19, atenderlos en un ambiente en donde puedan contraer la enfermedad como es el caso de un hospital, clínica o consulta dental puede significar un riesgo considerando su patología de base. La toma de decisiones debe hacerse en conjunto con el médico tratante y con el equipo de infectología y el procedimiento debe realizarse idealmente en un ambiente hospitalario que cuente con las condiciones para atender con seguridad al paciente.

\section{CONCLUSIÓN}

En caso de urgencias odontológicas que no puedan ser diferidas de atención, el personal de salud debe tomar todas las consideraciones necesarias presentadas en este documento. El lavado de manos y la desinfección pre y post atención de superficies de trabajo, inclusive el suelo, se mantiene como medida primordial. Se debe hacer uso obligatorio de elementos de bioseguridad para disminuir el riesgo de contagio, pantalla facial y mascarilla poseen un rol activo en la categoría de riesgo de exposición; así como utilizar delantal desechable para los procedimientos mencionados, debido a la cantidad de tiempo que el virus puede permanecer activo en superficies inertes. La toma de conocimiento de cada una de las recomendaciones para los diferentes tipos de urgencia odontológica disminuirá al mínimo las probabilidades de contagio entre paciente y profesionales.

SEPÚLVEDA, V. C.; SECCHI, A. A. \& DONOSO-HOFER, F. Urgency dental care considerations in the context of coronavirus COVID-19 (SARS-CoV-2). Int. J. Odontostomat., 14(3):279-284, 2020.

ABSTRACT: Coronaviruses are a family of viruses widely distributed in nature, mainly present in animals. Covid19 is the disease caused by the coronavirus (SARS-CoV-2), which was identified and characterized in January 2020 in China. Professionals in the dental area must take all protective measures when having to perform urgent care, hand washing and use of personal protective equipment. For each of the dental emergencies considered in the guide of the Chilean Ministry of Health, recommendations are given for action and subsequent waste and material sanitation. The objective of this review article is to provide updated and relevant recommendations to our national reality in order to reduce the chances of contagion in the face of the imminent exposure of patients who are suspected or who may present Covid-19

Covid-19.

KEYWORDS: Dental emergency, SARS-Cov2,

\section{REFERENCIAS BIBLIOGRÁFICAS}

Agnihotry, A.; Thompson, W.; Fedorowicz, Z.; van Zuuren, E. J. \& Sprakel, J. Antibiotic use for irreversible pulpitis. Cochrane Database Syst. Rev., 5:CD004969, 2019.

American Dental Association. What Constitutes a Dental Emergency? American Dental Association, 2020. Disponible en: 
success.ada.org/ /media/CPS/Files/Open\%20Files/ ADA_COVID19_Dental_Emergency_DDS. pdf?utm_source=adaorg\&utm_medium=covid-resourcesIp\&utm_content=cv-pm-emerg-def\&utm_campaign=covid$19 \&$ ga $=2.204309776 .1684020392 .1585245160$ 1734285265.1585245160

Grant, M.; Schramm, A.; Strong, B.; Buchbinder, D.; Ellis, E.; Wolvius, E. \& Sánchez Aniceto, G. AO CMF International Task Force Recommendations on Best Practices for Maxillofacial Procedures during COVID-19 Pandemic. 2020. Davos, AO CMF, 2020. Disponible en https://aocmf3.aofoundation.org/ ? $\mathrm{ga}=2.31078393 .791787372 .158534141$ 427436728.1585347141\#o=News\%20Date\%20Facet,Descending

Araya, S. C. Consideraciones para la atención de urgencia odontológica y medidas preventivas para COVID-19 (SARS-CoV 2). Int. J. Odontostomat., 14(3):268-70, 2020.

Consejo General de Colegios de Odontólogos y Estomatólogos de España. El nuevo Coronavirus 2019-nCOV y el Manejo del Paciente Dental. Actualización Coronavirus en Clínica Dental. Informe Técnico del Consejo General de Dentistas de España. Madrid, Consejo Dentistas Organización Colegial de Dentistas de España, 2020.

European Center for Disease Prevention and Control al 19 de marzo 2020.

Roser, M.; Ritchie, H. \& Ortiz-Ospina, E. Coronavirus Disease (COVID-19) - Statistics and Research. OurWorldInData.org., 2020, Disponible en: https://ourworldindata.org/coronavirus

Geller, C.; Varbanov, M. \& Duval, R. E. Human coronaviruses: insights into environmental resistance and its influence on the development of new antiseptic strategies. Viruses, 4(11):304468, 2012.

Ji, W.; Wang, W.; Zhao, X.; Zai, J. \& Li, X. Cross-species transmission of the newly identified coronavirus 2019-nCoV. J. Med. Virol., 92(4):433-40, 2020.

Kampf, G. Antiseptic Stewardship: Biocide Resistance and Clinical Implications. Cham, Springer International Publishing, 2018.

Liñares, J. \& Martín-Herrero, J. E. Bases farmacomicrobiológicas del tratamiento antibiótico de las enfermedades periodontales y periimplatarias. Av. Periodoncia Implantol. Oral, 15(3):139-47, 2003.

Maru, V. P.; Shakuntala, B. S. \& Nagarathna, C. Caries removal by chemomechanical (Carisolv ${ }^{\mathrm{TM}}$ ) vs. rotary drill: a systematic review. Open Dent. J., 9:462-72, 2015.

Meng, L.; Hua, F. \& Bian, Z. Coronavirus disease 2019 (COVID-19): emerging and future challenges for dental and oral medicine. $J$. Dent. Res., 12:22034520914246, 2020.

Ministerio de Salud (MINSAL). Guía Clínica Urgencias Odontológicas Ambulatorias. Santiago de Chile, Ministerio de Salud, Gobierno de Chile, 2011.

World Health Organization (WHO). Coronavirus disease 2019 (COVID-19). Situation Report - 70, 30 March 2020. Ginebra, World Health Organization, 2020. Disponible en: https:// www.who.int/docs/default-source/coronaviruse/situation-reports/ 20200330-sitrep-70-covid-19.pdf?sfvrsn=7e0fe3f8_2

Peng, X.; Xu, X.; Li, Y.; Cheng, L.; Zhou, X. \& Ren, B. Transmission routes of 2019-nCoV and controls in dental practice. Int. J. Oral Sci., 12:9, 2020. DOI: https://doi.org/10.1038/s41368-020-0075-9

Colegio Médico de Chile \& Sociedad Chilena de Infectología. COVID19. Información Relevante para Personal Sanitario. Santiago de Chile, Colegio Médico de Chile, Sociedad Chilena de Infectología, 2020. Disponible en: http://www.colegiomedico.cl/wp-content/ uploads/2020/03/Informacion relevante personal sanitario.pdf

Watanabe, A.; Tamaki, N.; Yokota, K.; Matsuyama, M. \& Kokeguchi, $\mathrm{S}$. Use of ATP bioluminescence to survey the spread of aerosol and splatter during dental treatments. J. Hosp. Infect., 99(3):303$5,2018$.
Dirección para correspondencia:

Cristóbal Sepúlveda Verdugo

Hospital San Juan de Dios

AV. Portales 3239

Santiago

CHILE

Email:cristobal.sepulvedav@gmail.com

Recibido : 30-03-2020

Aceptado: 31-03-2020 